\title{
Primary care physicians' perspectives towards managing rheumatoid arthritis: room for improvement
}

\author{
Katie L Garneau', Maura D Iversen ${ }^{1,2}$, Hsun Tsao $^{1}$ and Daniel H Solomon ${ }^{1,3^{*}}$
}

\begin{abstract}
Introduction: Many people with rheumatoid arthritis (RA) do not receive care from a rheumatologist. We surveyed primary care physicians (PCPs) to better understand their attitudes, knowledge, and practices regarding the optimal treatment of RA.

Methods: Randomly selected PCPs practicing in the US were surveyed. The survey encompassed their experience with RA, use of disease modifying anti-rheumatic drugs (DMARDs), and experience with rheumatology referrals. Logistic regression analyses described the responses and examined the correlation between physician variables and use of DMARDs.

Results: E-mail invitations were opened by 1, 103 PCPs and completed by 267 (25\%). Most respondents were men (68\%) in practice for over 10 years (64\%) who reported 6 or more RA patients under their care in the last year (71\%). The majority reported some RA training after medical school (59\%), but only one-third felt very confident managing this condition. Most (81\%) reported prescribing DMARDs, but 37\% do not initiate them, with only $9 \%$ reporting being very confident starting a DMARD. In unadjusted analyses, several respondent characteristics were strongly associated with not prescribing DMARDs, but none was significant after adjustment. Almost half (44\%) of PCPs noted that patients report difficulty getting appointments with rheumatologists.

Conclusions: We found many PCPs are uncomfortable managing RA with DMARDs, despite common beliefs that their patients lack access to a rheumatologist. Lack of accessibility to rheumatologists and discomfort in prescribing DMARDs for patients with RA are potential barriers to optimal treatment.
\end{abstract}

\section{Introduction}

Rheumatoid arthritis (RA) is the most common type of systemic inflammatory arthritis and causes substantial pain and disability [1]. The standard of care for RA has been well established by all professional organizations of rheumatology and includes the early initiation of disease-modifying anti-rheumatic drugs (DMARDs) $[2,3]$. Strong evidence supports such recommendations; early DMARD use demonstrated better long-term functional outcomes [4]. However, multiple studies from various settings show that many patients with RA do not use these drugs [5-8].

\footnotetext{
* Correspondence: dsolomon@partners.org

'Division of Rheumatology, Brigham and Women's Hospital, 75 Francis Street, PBB-B3, Boston, MA 02115, USA

Full list of author information is available at the end of the article
}

The strongest correlate of DMARD use across multiple studies is the involvement of a rheumatologist in the care of patients with RA [5,7]. Investigators have estimated that patients who see a rheumatologist are four to five times more likely to receive a DMARD than those who receive care from an internist or family practitioner [5,6]. Furthermore, at least two studies found a more favorable outcome for patients treated regularly by rheumatologists $[9,10]$. However, many patients with RA do not see rheumatologists.

Many factors play a role in the management of RA, but primary care physicians (PCPs) may play the biggest role since they are often the first and only point of contact for the patient. Thus, it is primarily up to the PCPs to use their own clinical knowledge to determine the 'course of action' to meet each patient's needs [11]. Studies on the management of RA have shown that, despite 
their abilities to diagnose RA, PCPs frequently choose not to refer patients with RA to a rheumatic disease expert; furthermore, it is rare for PCPs to initiate DMARD therapy $[12,13]$. Moreover, even when PCPs refer patients with RA to rheumatologists, there are too few rheumatologists to adequately care for the growing population in need of rheumatic disease expertise [9,14]. The shortage of rheumatologists manifests as long wait times for rheumatology visits or lack of rheumatology referral altogether or both [13]. Despite this evidence of a rheumatologist shortage, relatively little is known about PCPs' interactions with patients with RA [14]. Therefore, it is important to explore the factors that are related to PCPs' management of RA and that may present barriers to recommended RA care. Our aim was to study PCPs' attitudes, knowledge, and practices regarding optimal treatment of RA, including DMARD use and rheumatology referral.

\section{Materials and methods Survey participants}

Participant recruitment was achieved through collaboration with a survey vendor that has access to the American Medical Association physician directory. Through this vendor, we sent e-mails to 5,331 randomly selected physicians who had e-mail addresses in the American Medical Association physician directory and who had self-designated as 'family medicine', 'general practice', or 'internal medicine' providers. Each physician was sent the e-mail on two occasions approximately 1 month apart. The e-mail invitation included a link to the webbased survey. A $\$ 75$ honorarium gift card was offered for completion of the survey. The study protocol and survey were approved by the institutional review board of Partners' Healthcare. Informed consent was implied by PCPs' completion of the survey.

\section{Survey}

The survey consisted of sociodemographic information as well as RA-specific items. The RA-specific items focused on the respondents' experience with RA as well as their attitudes and knowledge of RA, DMARDs, and rheumatology referrals. Experience with RA was gauged through the respondents' years in practice and current number of patients with RA. Other questions ascertained physicians' attitudes and level of confidence toward referring patients with RA to rheumatologists, diagnosing RA, and prescribing DMARDs to patients with RA. Knowledge questions dealt with the appropriateness of DMARDs in RA as well as with RA training that respondents may have received beyond medical school. The survey ended with an open-ended item asking subjects whether they had any ideas for improving care for patients with RA.

\section{Statistical analysis}

The statistical analyses described the survey responses by calculating means and frequencies. We stratified survey responses according to whether respondents reported DMARD prescribing or not. Also, survey responses were stratified on the basis of the likelihood of referral to rheumatologists. Correlates of DMARD prescribing were examined in logistic regression models that calculated the odds ratio for prescribing and $95 \%$ confidence intervals. We assessed the odds ratios for all variables and then advanced selected variables with $P$ values of less than 0.10 to a multivariable logistic regression model. All analyses were conducted with SAS 9.1 (SAS Institute Inc., Cary, NC, USA).

\section{Results}

Invitations were sent by e-mail to 5,331 physicians; 1 , $103(20.7 \%)$ opened the e-mail and 756 opened the survey. Of those who opened the survey, 275 (36\%) started the survey and 272 completed the survey. Five were removed from our analysis because we discovered, from their answer to an open-ended question regarding RA education beyond medical school, that they had training in rheumatology. Our total sample consisted of 267 subjects (Figure 1).

Characteristics of our sample are shown in Table 1. The majority of our sample reported being in medical practice for more than 10 years. The sample consisted of physicians representing all regions of the US. Almost two thirds of the physicians in our sample see 10 or fewer patients with RA per year. The majority of our sample stated that they were 'somewhat confident' in their ability to diagnose RA, and approximately one third described themselves as 'very confident'. Over half of the sample stated that they had received additional RA education beyond medical school; 'journals or textbooks' (39\%) followed by 'residency' (37\%) were the most cited educational sources. Other popular sources of RA education included 'grand rounds', 'other continuing medical education', and 'online continuing medical education'.

We explored DMARD prescribing patterns in the survey (Table 2). Approximately one fifth of subjects stated that they did not prescribe DMARDs. Of the 217 who reported prescribing DMARDs, $45 \%$ stated that they had only continued a prescription (initially written by another physician), 9\% stated that they had only initiated DMARDs, and the remainder reported writing first prescriptions and continued prescriptions. The most frequently prescribed DMARDs were non-biologics such as methotrexate, hydroxychloroquine, and sulfasalazine. However, $44 \%$ of prescribers reported prescribing biologic DMARDs.

When asked what the best time to initiate DMARD therapy was, a little over one half of subjects chose 


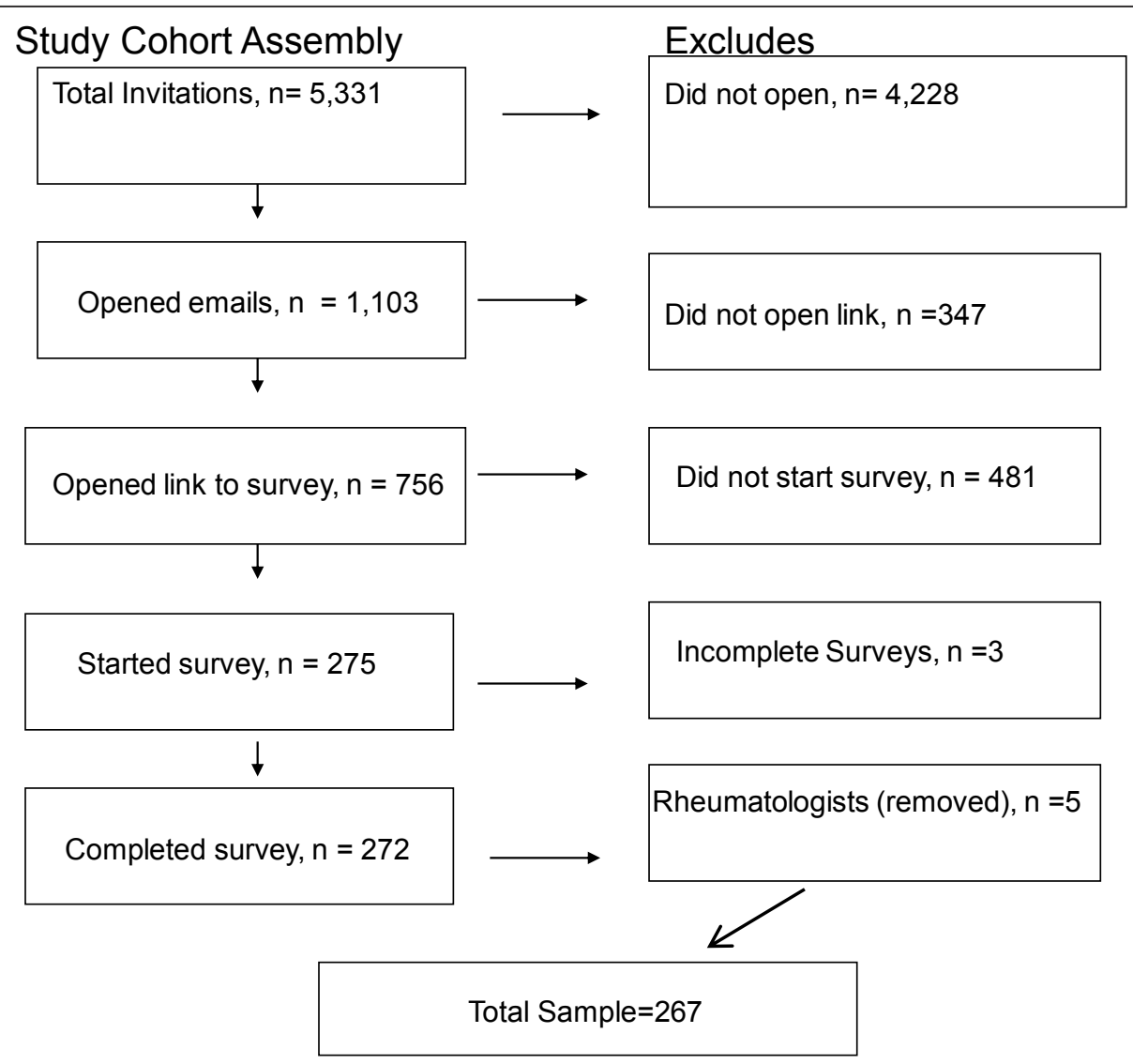

Figure 1 describes the assembly of the cohort.

'within the first 6 months of diagnosis', whereas 35\% chose 'after a trial of NSAIDs [non-steroidal anti-inflammatory drugs] or steroids', and 5\% chose 'at least 6 months after diagnosis'. Less than $10 \%$ of subjects reported being very comfortable initiating DMARDs. The majority (61\%) of subjects stated that they were 'somewhat uncomfortable' or 'very uncomfortable' starting a DMARD; however, almost half (49\%) stated that they were 'somewhat comfortable' continuing DMARD therapy. Common reasons cited for discomfort using DMARDs included 'toxicities', 'infections', and 'intravenous therapy'.

To better understand physician correlates of reporting not prescribing DMARDs, we examined the probabilities of DMARD use in logistic regression models (Table 3). In unadjusted analyses, we found several strong correlates of not prescribing DMARDs, such as fewer years in practice, fewer patients with RA, lower confidence diagnosing RA, belief that less than half of patients with RA are good candidates for DMARDs, and lacking sufficient knowledge of DMARDs. However, none of these variables was statistically significant in adjusted analyses.

The majority $(71 \%)$ of our sample stated that they were very likely to refer patients with RA to a specialist
(Table 4). When the question 'Under what situations would you refer your patients to a rheumatologist?' was asked, 'advanced disease' was the most cited reason, followed by 'patient desire' and 'uncomfortable prescribing DMARDs'. However, approximately one quarter reported that patients had difficulty getting appointments with rheumatologists. All of the physicians who were unlikely to refer gave 'no need' as their reason for not referring. However, they stated that they would refer if the patient desired. Some answers respondents gave when asked to describe 'other' reasons for referring their patients to rheumatologists included 'if they have insurance', 'for biologics or for medications requiring intravenous infusion', 'if not responding to DMARDs or failing NSAIDs', and 'compliance'. Some of the main reasons the PCPs in our sample did not refer included 'insurance problems', 'too difficult to get a rheumatology appointment', and 'no need'. Seven percent of the total sample stated their reason for not referring as 'do not know a practicing rheumatologist'.

\section{Discussion}

We studied the prescribing and referring habits of a national sample of PCPs who took part in an e-mailed 
Table 1 Characteristics of survey respondents $(n=267)$

\begin{tabular}{|c|c|}
\hline & $\begin{array}{c}\text { Number } \\
\text { (percentage) }\end{array}$ \\
\hline Female gender ${ }^{a}$ & $86(32 \%)$ \\
\hline \multicolumn{2}{|l|}{ Years practicing medicine } \\
\hline $0-1$ & $4(1 \%)$ \\
\hline $2-5$ & $43(16 \%)$ \\
\hline $6-10$ & $50(19 \%)$ \\
\hline $11-15$ & $40(15 \%)$ \\
\hline $16+$ & $130(49 \%)$ \\
\hline \multicolumn{2}{|l|}{ Region of practice } \\
\hline West & $125(47 \%)$ \\
\hline Midwest & $41(15 \%)$ \\
\hline Northeast & $14(5 \%)$ \\
\hline South & $86(32 \%)$ \\
\hline \multicolumn{2}{|l|}{ RA patients seen in last year } \\
\hline $0-5$ & 77 (29\%) \\
\hline $6-10$ & $91(34 \%)$ \\
\hline $11+$ & $99(37 \%)$ \\
\hline \multicolumn{2}{|l|}{ Confidence in ability to diagnose RA } \\
\hline Very confident & $83(31 \%)$ \\
\hline Somewhat confident & $161(61 \%)$ \\
\hline Less than confident & $19(7 \%)$ \\
\hline No confidence & $3(1 \%)$ \\
\hline \multicolumn{2}{|l|}{$\begin{array}{l}\text { Additional RA education beyond medical } \\
\text { school }\end{array}$} \\
\hline Yes & $156(59 \%)$ \\
\hline \multicolumn{2}{|l|}{ Source of training regarding RA } \\
\hline Residency & $100(37 \%)$ \\
\hline Fellowship & $4(2 \%)$ \\
\hline Grand rounds & $59(22 \%)$ \\
\hline Online continuing medical education & $54(20 \%)$ \\
\hline Other continuing medical education & $59(22 \%)$ \\
\hline Journals or textbooks or both & $104(39 \%)$ \\
\hline Other conferences & $48(18 \%)$ \\
\hline Other & $3(1 \%)$ \\
\hline
\end{tabular}

${ }^{\mathrm{a}}$ Six missing. RA, rheumatoid arthritis.

survey. Most of our subjects had more than 10 years of practice and saw six or more patients with RA in the last year. Nearly all subjects felt either somewhat confident or very confident in their ability to diagnose RA, and most had received additional RA education beyond medical school. Approximately one fifth of respondents reported not prescribing DMARDs, and although $46 \%$ of those who did claim to prescribe DMARDs stated that they would both initiate and continue DMARD therapy, $45 \%$ stated that they would only continue DMARD therapy and 9\% stated they would only initiate DMARDs. Of the $81 \%$ of our sample who reported prescribing a DMARD, just over half stated that they were either 'somewhat' or 'very' uncomfortable starting a DMARD. Most of our sample stated that they would refer their patients with RA to rheumatologists, but $44 \%$ noted that patients report difficulty getting appointments with a rheumatologist.

These results suggest that PCPs commonly continue DMARDs but that a minority initiate them. A high level of discomfort prescribing DMARDs with difficulty accessing rheumatology referrals may underpin reports of suboptimal prescribing of DMARDs. There is also evidence of early use of DMARDs; however, $40 \%$ of those PCPs who prescribe DMARDs report that delayed initiation is appropriate (Table 2). This 'wait and see' approach implies a lack of urgency toward aggressive treatment and may contribute to the 'no need' attitude, felt by some, for referral to a rheumatologist (Table 4).

Furthermore, when asked what factors make patients inappropriate candidates for DMARD therapy, approximately half of the total respondents reported that there was no need for a DMARD, one third noted patients were too sick to get a DMARD, and more than half felt that side effects of DMARDs were too problematic (Table 2). Other concerns raised were drug interactions and the cost of medications and their monitoring. We asked our sample to give ideas for improving patient care in regard to RA. The most popular idea was further training and education to improve comfort level diagnosing RA and prescribing treatment. Much of our sample saw a need for more continuing medical education, and several requested a treatment algorithm to follow. Another frequently cited idea by respondents for improving RA care was increased access to rheumatologists for consultation and patient appointments as well as more patient education regarding RA and DMARD therapy.

The literature exploring PCPs' referring and prescribing habits in regard to RA management is limited. One study in Ontario, Canada, conducted a survey using a case scenario to examine PCPs' management of RA and found that most physicians would diagnose RA properly; however, rates of referral to specialists tended to be low [13]. Another Canadian study surveyed family physicians in Quebec and found that the vast majority of physicians would make proper RA diagnoses in a vignette case and that about three fourths said that they would refer patients to a rheumatic disease specialist; however, only $4 \%$ mentioned initiating DMARD therapy [12].

Our findings were similar to those of the aforementioned studies in regard to the ability and confidence of PCPs to make a proper diagnosis; however, the Ontario study showed that rates of referral were low whereas our sample's rate of referral was high. The Quebec study, like ours, showed that the majority of PCPs would refer patients with RA to specialists; however, only $4 \%$ mentioned initiating DMARD therapy whereas $80 \%$ of our sample stated that they would prescribe DMARDs. Our study is more recent, and this may explain the different attitudes of PCPs to the use of DMARDs. Additionally, 
Table 2 Information on prescribing disease-modifying anti-rheumatic drugs

\begin{tabular}{|c|c|c|c|}
\hline & $\begin{array}{c}\text { Total } \\
n=266^{\mathrm{b}}\end{array}$ & $\begin{array}{c}\text { DMARD prescribers }^{\mathrm{a}} \\
\quad n=217\end{array}$ & $\begin{array}{l}\text { DMARD non-prescribers } \\
\qquad n=49\end{array}$ \\
\hline \multicolumn{4}{|l|}{ Initial prescription, continuation, or both } \\
\hline First only & & $20(9 \%)$ & \\
\hline Continuation only & & $98(45 \%)$ & \\
\hline Both & & $99(46 \%)$ & \\
\hline \multicolumn{4}{|l|}{ Prescribed DMARDs } \\
\hline Methotrexate & & $195(90 \%)$ & \\
\hline Hydroxychloroquine & & $171(79 \%)$ & \\
\hline Sulfasalazine & & $135(62 \%)$ & \\
\hline Leflunomide & & $43(20 \%)$ & \\
\hline Gold & & $35(16 \%)$ & \\
\hline Azathioprine & & $54(25 \%)$ & \\
\hline Cyclosporine & & $32(15 \%)$ & \\
\hline Abatacept & & $8(4 \%)$ & \\
\hline Etanercept & & $64(29 \%)$ & \\
\hline Infliximab & & $56(26 \%)$ & \\
\hline Rituximab & & $20(9 \%)$ & \\
\hline Adalimumab & & $43(20 \%)$ & \\
\hline Certolizumab pegol & & $2(1 \%)$ & \\
\hline Golimumab & & $1(0 \%)$ & \\
\hline \multicolumn{4}{|l|}{ Type of DMARDs prescribed ${ }^{a}$} \\
\hline Biologic and non-biologic DMARDs & & $96(44 \%)$ & \\
\hline Non-biologic DMARDs only & & $118(54 \%)$ & \\
\hline Biologic DMARDs only & & $2(1 \%)$ & \\
\hline \multicolumn{4}{|c|}{ Factors that make patients inappropriate candidates for DMARDs } \\
\hline No need (well controlled without DMARDs) & $131(49 \%)$ & $110(51 \%)$ & $21(43 \%)$ \\
\hline Too sick to take a DMARD & $92(35 \%)$ & $78(36 \%)$ & $14(29 \%)$ \\
\hline Side effects of DMARDs too problematic & $148(56 \%)$ & $128(59 \%)$ & $20(41 \%)$ \\
\hline Drug interactions & $83(31 \%)$ & $74(34 \%)$ & $9(18 \%)$ \\
\hline Drug cost and monitoring are too high & $142(55 \%)$ & $115(53 \%)$ & $27(55 \%)$ \\
\hline Cannot get laboratory monitoring & $20(8 \%)$ & $17(8 \%)$ & $3(6 \%)$ \\
\hline \multicolumn{4}{|l|}{ Best time to initiate DMARDs } \\
\hline After a trial of NSAIDs or steroids & $92(35 \%)$ & $75(35 \%)$ & $17(35 \%)$ \\
\hline Within the first 6 months of diagnosis & $159(60 \%)$ & $132(61 \%)$ & $27(55 \%)$ \\
\hline At least 6 months after diagnosis & $13(5 \%)$ & $9(4 \%)$ & $4(8 \%)$ \\
\hline \multicolumn{4}{|l|}{ Comfort level starting a DMARD ${ }^{c}$} \\
\hline Very comfortable & $23(9 \%)$ & $23(11 \%)$ & $0(0 \%)$ \\
\hline Somewhat comfortable & 79 (30\%) & $73(34 \%)$ & $6(12 \%)$ \\
\hline Somewhat uncomfortable & $112(42 \%)$ & $89(41 \%)$ & $23(47 \%)$ \\
\hline Very uncomfortable & $50(19 \%)$ & $30(14 \%)$ & $20(41 \%)$ \\
\hline \multicolumn{4}{|l|}{ Comfort level continuing a DMARD } \\
\hline Very comfortable & $75(28 \%)$ & $71(33 \%)$ & $4(8 \%)$ \\
\hline Somewhat comfortable & $130(49 \%)$ & $107(50 \%)$ & $23(47 \%)$ \\
\hline Somewhat uncomfortable & $54(20 \%)$ & $37(17 \%)$ & $17(35 \%)$ \\
\hline Very uncomfortable & $6(2 \%)$ & $1(0 \%)$ & $5(10 \%)$ \\
\hline
\end{tabular}

${ }^{a}$ One prescriber did not fill in types of disease-modifying anti-rheumatic drugs (DMARDs). ${ }^{b}$ One missing response. ${ }^{\mathrm{C}}$ Three missing responses. ${ }^{\mathrm{d}}$ Two missing responses. NSAID, non-steroidal anti-inflammatory drug.

differences may be due to different structures of the health-care systems. One additional difference that may be important to note between our study and these Canadian studies is the difference in response rates. Whereas studies by Bernatsky and colleagues [12] and Glazier and colleagues [13] yielded response rates of $31 \%$ and $68 \%$, respectively, our study produced a response rate of only $25 \%$. Possible reasons for this difference might be that the two 


\begin{tabular}{|c|c|c|}
\hline & $\begin{array}{l}\text { Univariate, } \\
\text { OR }(95 \% \mathrm{Cl})\end{array}$ & $\begin{array}{l}\text { Multivariate }{ }^{a} \text {, } \\
\text { OR (95\% Cl) }\end{array}$ \\
\hline \multicolumn{3}{|l|}{ Years practicing medicine } \\
\hline $0-1$ & $5.07(0.69-37)$ & $1.44(0.14-14.83)$ \\
\hline $2-10$ & $1.30(0.68-2.49)$ & $0.98(0.48-2.01)$ \\
\hline $11+$ & 1 & 1 \\
\hline \multicolumn{3}{|l|}{ RA patients seen in last year } \\
\hline $0-5$ & $2.46(1.30-4.67)$ & $1.74(0.85-3.58)$ \\
\hline $6+$ & 1 & 1 \\
\hline \multicolumn{3}{|l|}{ Confidence in ability to diagnose RA } \\
\hline Very of somewhat confident & 1 & 1 \\
\hline Less than or no confidence & $3.53(1.41-8.82)$ & $2.07(0.72-5.95)$ \\
\hline \multicolumn{3}{|c|}{ Additional RA education beyond medical school } \\
\hline Yes & 1 & 1 \\
\hline No & $1.46(0.79-2.73)$ & $0.92(0.45-1.89)$ \\
\hline \multicolumn{3}{|c|}{ Proportion of RA patients who are good candidates for DMARDs } \\
\hline $0 \%-50 \%$ & $2.88(1.22-6.82)$ & $2.41(0.96-6.08)$ \\
\hline $51 \%-75 \%$ & $1.01(0.39-2.59)$ & $0.85(0.31-2.32)$ \\
\hline $76 \%-100 \%$ & 1 & 1 \\
\hline \multicolumn{3}{|l|}{ Physicians' knowledge level of DMARDs } \\
\hline Very knowledgeable & 1 & 1 \\
\hline Somewhat knowledgeable & $2.13(0.27-16)$ & $1.22(0.15-10.2)$ \\
\hline Lacking sufficient or any knowledge & $9.87(1.23-79)$ & $5.20(0.60-44)$ \\
\hline
\end{tabular}

${ }^{a}$ Multivariate model included all variables shown in the table. $\mathrm{Cl}$, confidence interval; DMARD, disease-modifying anti-rheumatic drug; OR, odds ratio; RA, rheumatoid arthritis.

Canadian studies mailed surveys via conventional mail whereas our surveys were internet-based and that the Canadian studies repeated their mailings at least two times whereas we did only one follow-up mailing. Additionally, we do not know what type of incentive the Canadian researchers offered their respondents for completing the survey and therefore these studies cannot be compared with ours.

Several limitations of this research are important to note. There are several issues regarding generalizability

Table 4 Factors influencing referral to rheumatologist for rheumatoid arthritis

\begin{tabular}{|c|c|c|c|c|}
\hline & \multirow[b]{2}{*}{$\begin{array}{l}\text { Total cohort } \\
\left(n=266^{\mathrm{a}}\right)\end{array}$} & \multicolumn{3}{|c|}{ Likelihood of referring } \\
\hline & & $\begin{array}{c}\text { Very likely } \\
(n=189)\end{array}$ & $\begin{array}{l}\text { Possible } \\
(n=73)\end{array}$ & $\begin{array}{c}\text { Unlikely } \\
(n=4)\end{array}$ \\
\hline \multicolumn{5}{|l|}{ Situations leading up to referral } \\
\hline Advanced disease & $213(80 \%)$ & $153(81 \%)$ & $60(82 \%)$ & $0(0 \%)$ \\
\hline Patient desire for a referral & $211(79 \%)$ & $153(81 \%)$ & $54(74 \%)$ & $4(100 \%)$ \\
\hline Uncomfortable prescribing DMARDs & $186(70 \%)$ & $152(80 \%)$ & $33(45 \%)$ & $1(25 \%)$ \\
\hline Patient comorbidities & $107(40 \%)$ & $85(45 \%)$ & $20(27 \%)$ & $2(50 \%)$ \\
\hline Other & $14(5 \%)$ & $11(6 \%)$ & $3(4 \%)$ & $0(0 \%)$ \\
\hline \multicolumn{5}{|c|}{ Patients report of difficulty getting rheumatology appointment ${ }^{\mathrm{b}}$} \\
\hline Yes, most of the time & $74(44 \%)$ & $49(40 \%)$ & $25(57 \%)$ & $0(0 \%)$ \\
\hline No, never & $95(56 \%)$ & $74(60 \%)$ & $19(43 \%)$ & $2(50 \%)$ \\
\hline \multicolumn{5}{|l|}{ Main reason for not referring } \\
\hline Do not know a rheumatologist & $19(7 \%)$ & $10(5 \%)$ & $9(12 \%)$ & $0(0 \%)$ \\
\hline Rheumatology appointment too difficult to get & $73(27 \%)$ & $46(24 \%)$ & $27(37 \%)$ & $0(0 \%)$ \\
\hline No need & $63(24 \%)$ & $32(17 \%)$ & $27(37 \%)$ & $4(100 \%)$ \\
\hline Insurance problems & $107(40 \%)$ & $74(39 \%)$ & $33(45 \%)$ & $0(0 \%)$ \\
\hline Other & $48(18 \%)$ & $37(20 \%)$ & $11(15 \%)$ & $0(0 \%)$ \\
\hline
\end{tabular}

${ }^{a}$ One missing response. ${ }^{b}$ One hundred three missing responses because of an error in the electronic survey. DMARD, disease-modifying anti-rheumatic drug. 
with internet surveys. One author [15] noted that respondents who answer internet-based surveys are those who are keyboard and internet literate - currently only a third of the adult population in the US. Second, internet based surveys frequently confuse respondents in their instructions. A third problem noted was a lack of time, leading to some respondents' preference to take the survey in locations other than online. It was suggested that respondents may then choose to print out the survey and take it in another location, and this would potentially exclude these respondents' answers, creating a bias [15]. There was also a relatively low response rate. Of those who opened the e-mail, 25\% completed the survey. This response rate, while lower than one might hope, is similar to that of other e-mailed surveys [16]. Additionally, literature supporting the reliability of internet questionnaires as a surveying tool exists [17]. Our survey was not a validated questionnaire but a compilation of questions that regarded attitudes toward and knowledge about RA and that deserved further attention. Finally, we were unable to determine whether respondents were representative of the entire sample with regard to demographics.

\section{Conclusions}

We surveyed a US sample of PCPs in regard to the management of RA. We found that many PCPs are uncomfortable managing RA with DMARDs, despite common beliefs that their patients lack access to a rheumatologist. Lack of accessibility to rheumatologists and discomfort in prescribing DMARDs for patients with RA are potential barriers to optimal treatment. Future directions for research into improving RA care may include the design of educational programs for PCPs to gain greater comfort prescribing DMARDs. It might also be prudent to develop ways in which rheumatic disease specialists can work more closely with PCPs to treat RA by using a 'team' approach. Such models have been developed for diabetes and depression $[18,19]$. Other options for improving treatment would be to further involve non-physician providers, such as nurse practitioners or physician assistants, in managing DMARDs. If such approaches are found to be effective, RA management may be improved substantially.

\section{Abbreviations \\ DMARD: disease-modifying anti-rheumatic drug; NSAID: non-steroidal anti- inflammatory drug; PCP: primary care physician; RA: rheumatoid arthritis.}

\section{Author details}

'Division of Rheumatology, Brigham and Women's Hospital, 75 Francis Street, PBB-B3, Boston, MA 02115, USA. ²Department of Physical Therapy School of Health Professions, Bouve College of Health Sciences Northeastern University, 6 Robinson Hall, Room 301C, 360 Huntington Avenue, Boston, MA 02115, USA. 'BDivision of Pharmacoepidemiology, Brigham and Women's Hospital, 1620 Tremont Street, Suite 3030, Boston, MA 02120, USA.

\section{Authors' contributions}

KLG participated in drafting the survey, data collection, and manuscript preparation. MDI participated in drafting the survey, data analysis, and manuscript preparation. HT participated in data analysis. DHS conceived of the study and participated in design of the study, drafting of the survey, data analysis, and manuscript preparation. All authors read and approved the final manuscript.

\section{Competing interests}

DHS has received research support from Amgen (Thousand Oaks, CA, USA), Abbott (Abbott Park, IL, USA), and Lilly (Indianapolis, IN, USA) and directed an educational course funded by Bristol-Myers Squibb (Princeton, NJ, USA). He has also participated in an unpaid role in several trials funded by Pfizer Inc (New York, NY, USA) but these trials were not about rheumatoid arthritis. The other authors declare that they have no competing interests.

Received: 19 July 2011 Revised: 3 November 2011

Accepted: 18 November 2011 Published: 18 November 2011

\section{References}

1. Pincus T, Callahan LF, Sale WG, Brooks AL, Payne LE, Vaughn WK: Severe functional declines, work disability, and increased mortality in seventyfive rheumatoid arthritis patients studied over nine years. Arthritis Rheum 1984, 27:864-872.

2. Saag KG, Teng GG, Patkar NM, Anuntiyo J, Finney C, Curtis JR, Paulus HE, Mudano A, Pisu M, Elkins-Melton M, Outman R, Allison JJ, Suarez Almazor M, Bridges SL Jr, Chatham WW, Hochberg M, MacLean C, Mikuls T, Moreland LW, O'Dell J, Turkiewicz AM, Furst DE, American College of Rheumatology: American College of Rheumatology 2008 recommendations for the use of nonbiologic and biologic diseasemodifying antirheumatic drugs in rheumatoid arthritis. Arthritis Rheum 2008, 59:762-784.

3. Smolen JS, Landewé R, Breedveld FC, Dougados M, Emery P, GaujouxViala C, Gorter S, Knevel R, Nam J, Schoels M, Aletaha D, Buch M, Gossec L, Huizinga T, Bijlsma JW, Burmester G, Combe B, Cutolo M, Gabay C, GomezReino J, Kouloumas M, Kvien TK, Martin-Mola E, Mclnnes I, Pavelka K, van Riel P, Scholte M, Scott DL, Sokka T, Valesini G, van Vollenhoven R, Winthrop KL, Wong J, Zink A, van der Heijde D: EULAR recommendations for the management of rheumatoid arthritis with synthetic and biological disease-modifying antirheumatic drugs. Ann Rheum Dis 2010, 69:964-975.

4. Finckh $\mathrm{A}$, Liang $\mathrm{MH}$, van Herckenrode $\mathrm{CM}$, de Pablo P: Long-term impact of early treatment on radiographic progression in rheumatoid arthritis: a meta-analysis. Arthritis Rheum 2006, 55:864-872.

5. Schmajuk G, Schneeweiss S, Katz JN, Weinblatt ME, Setoguchi S, Avorn J, Levin R, Solomon DH: Treatment of older adult patients diagnosed with rheumatoid arthritis: improved but not optimal. Arthritis Rheum 2007, 57:928-934.

6. Lacaille D, Anis AH, Guh DP, Esdaile JM: Gaps in care for rheumatoid arthritis: a population study. Arthritis Rheum 2005, 53:241-248.

7. Widdifield J, Bernatsky S, Paterson JM, Thorne JC, Cividino A, Pope J, Gunraj N, Bombardier C: Quality care in seniors with new-onset rheumatoid arthritis: a Canadian perspective. Arthritis Care Res (Hoboken) 2011, 63:53-57.

8. Schmajuk G, Trivedi AN, Solomon DH, Yelin E, Trupin L, Chakravarty EF, Yazdany J: Receipt of disease-modifying antirheumatic drugs among patients with rheumatoid arthritis in Medicare managed care plans. JAMA 2011, 305:480-486.

9. Shipton D, Glazier RH, Guan J, Badley EM: Effects of use of specialty services on disease-modifying antirheumatic drug use in the treatment of rheumatoid arthritis in an insured elderly population. Med Care 2004, 42:907-913.

10. Yelin EH, Such CL, Criswell LA, Epstein WV: Outcomes for persons with rheumatoid arthritis with a rheumatologist versus a non-rheumatologist as the main physician for this condition. Med Care 1998, 36:513-522.

11. Foley KA, Denke MA, Kamal-Bahl S, Simpson R Jr, Berra K, Sajjan S, Alexander CM: The impact of physician attitudes and beliefs on treatment decisions: lipid therapy in high-risk patients. Med Care 2006, 44:421-428. 
12. Bernatsky S, Feldman D, Shrier I, Toupin K, Haggerty J, Tousignant P, Zummer M: Care pathways in early rheumatoid arthritis. Can Fam Physician 2006, 52:1444-1445.

13. Glazier RH, Dalby DM, Badley EM, Hawker GA, Bell MJ, Buchbinder R, Lineker SC: Management of the early and late presentations of rheumatoid arthritis: a survey of Ontario primary care physicians. CMAJ 1996, 155:679-687.

14. Deal CL, Hooker R, Harrington T, Birnbaum N, Hogan P, Bouchery E, KleinGitelman M, Barr W: The United States rheumatology workforce: supply and demand, 2005-2025. Arthritis Rheum 2007, 56:722-729.

15. Wyatt JC: When to use Web-based surveys. J Am Med Inform Assoc 2000, 7:426-429.

16. Sheehan K: E-mail surveys response rates: a review. Journal of ComputerMediated Communication 2006, 6:0[http://www.ascusc.org/jcmc/vol4/issue3/ ].

17. Ritter $\mathrm{P}$, Lorig $\mathrm{K}$, Laurent $\mathrm{D}$, Matthews $\mathrm{K}$ : Internet versus mailed questionnaires: a randomized comparison. J Med Internet Res 2004, 6:e29.

18. Katon WJ, Von Korff M, Lin EH, Simon G, Ludman E, Russo J,

Ciechanowski P, Walker E, Bush T: The Pathways Study: a randomized trial of collaborative care in patients with diabetes and depression. Arch Gen Psychiatry 2004, 61:1042-1049.

19. Greenfield S: Defining and understanding 'co-management' care. Diabetes Care 2002, 25:1657-1658.

doi:10.1186/ar3517

Cite this article as: Garneau et al.: Primary care physicians' perspectives towards managing rheumatoid arthritis: room for improvement. Arthritis Research \& Therapy 2011 13:R189.

\section{Submit your next manuscript to BioMed Central} and take full advantage of:

- Convenient online submission

- Thorough peer review

- No space constraints or color figure charges

- Immediate publication on acceptance

- Inclusion in PubMed, CAS, Scopus and Google Scholar

- Research which is freely available for redistribution

Submit your manuscript at www.biomedcentral.com/submit 